\title{
Recent Developments in the Installation of Carbon Contact Strips on Pantograph Heads
}

\author{
Shunichi KUBO \\ Senior Researcher, Laboratory Head, Frictional Materials G., Materials Technology Div. \\ Hiroshi TSUCHIYA \\ Assistant Senior Researcher, Frictional Materials G., Materials Technology Div. \\ The method for installing carbon-based contact strips on pantograph heads is very \\ important from the operational point of view. Carbon contact strips are generally manu- \\ factured with a dovetail base that can be clad with a close-fitting steel sheath, or a fabri- \\ cated metal holder that grips a full-length carbon strip and has installation bolts for \\ mounting on a pantograph head. The authors have developed three other installation \\ methods. This paper describes the development of carbon-based contact strip materials \\ over the past two decades in Japan, and the results of laboratory or field tests on the \\ installation methods that have been developed.
}

Keywords: Contact strip, metal-impregnated carbon, pantograph head

\section{Introduction}

It is well known that the use of carbon materials in pantograph contact strips is an effective way of reducing contact wire wear. A number of railways in Europe use carbon contact strips not only for local but also for highspeed trains.

The former Japanese National Railways (JNR) never used carbon materials because of their high electrical resistivity and low mechanical strength, opting for sintered metal alloys on their trains, including Shinkansen, for five decades. To decrease contact wire wear, carbon contact strips with an electrical resistivity lower than 3 $\mu \Omega m$ were developed just after the privatization of JNR in 1987 and tested in the latter half of the 1980s. These have subsequently replaced the sintered metal alloys. Currently, these materials are being used on more than $60 \%$ of the DC electric vehicles of six Japan Railway (JR) companies.

This paper provides a short summary of the developments of carbon-based contact strips being used on DC electric vehicles and those for various other types of electric vehicles.

\section{Developments in carbon-based contact strip materials over the past two decades in Japan}

\subsection{Carbon-based contact strip materials with lower resistivity}

To use carbon materials safely as pantograph contact strips on DC electric vehicles, which are predominantly used on JR companies' narrow-gauge lines, the temperature of the contact wire in contact with the contact strip when at a standstill has to be below the maximum limit of $90{ }^{\circ} \mathrm{C}$ under the following conditions:

(1) The maximum electric current per pantograph when stationary is about $100 \mathrm{~A}$.
(2) The maximum atmospheric temperature is $40{ }^{\circ} \mathrm{C}$.

(3) The pantograph uplift force is $49 \mathrm{~N}$.

(4) A simple catenary is used.

To keep the temperature of the contact wire at the contact point below $90{ }^{\circ} \mathrm{C}$, the maximum permissible temperature rise is limited to only $50 \mathrm{~K}$.

Meeting all of these conditions presents the use of carbon materials with severe problems when compared with those in conventional cases. It is therefore difficult for JR companies to use those carbon materials, which are widely used in Europe, that have an electrical resistivity of about $7 \mu \Omega \mathrm{m}$. Table 1 shows the typical carbonbased contact strip materials used in Japan, classified by resistivity.

According to past experiments, the electrical resistivity of the contact strip material must be lower than 3 $\mu \Omega \mathrm{m}$ to keep temperature rises below $50 \mathrm{~K}$. Figure 1 shows some experimental results of temperature rise near the contact point when an electric current of $100 \mathrm{~A}$ passes through the contact point between a strip and the wire. In the latter half of the $1980 \mathrm{~s}$, carbon-based materials with a resistivity of less than $3 \mu \Omega \mathrm{m}$ were developed to replace the conventional sintered metal alloys. Currently, these materials are being used on more than $60 \%$ of the DC electric vehicles of six JR companies. ${ }^{1), 2)}$

Table 1 Typical carbon-based contact strip materials in Japan

\begin{tabular}{|l|l|l||l|}
\hline \multicolumn{1}{|c|}{$\begin{array}{c}\text { Resistivity } \\
(\mu \Omega \mathrm{m})\end{array}$} & Grade & \multicolumn{1}{|c|}{ Type of material } & $\begin{array}{l}\text { European equivalent } \\
\text { in terms of resistivity }\end{array}$ \\
\hline Higher than 10 & SW & Pure carbon (not used by JR) & CY3TA, AR129 \\
\hline $3 \sim 10$ & MC15 & Sn-Sb alloy impregnated carbon & MY7D, P5279 \\
\hline $1 \sim 3$ & $\begin{array}{l}\text { PC78 } \\
\text { PC78A }\end{array}$ & $\begin{array}{l}\text { Cu alloy impregnated carbon } \\
\text { Cu impregnated carbon }\end{array}$ & MY258 \\
\cline { 2 - 4 } & PC58 & Cu powder mixed carbon & \\
\cline { 2 - 5 } & AN3 & $\begin{array}{l}\text { Cu-Ti alloy impregnated } \\
\text { C/C composite }\end{array}$ & \\
\hline Lower than 1 & TM1 & Cu impregnated carbon & (None) \\
\hline
\end{tabular}




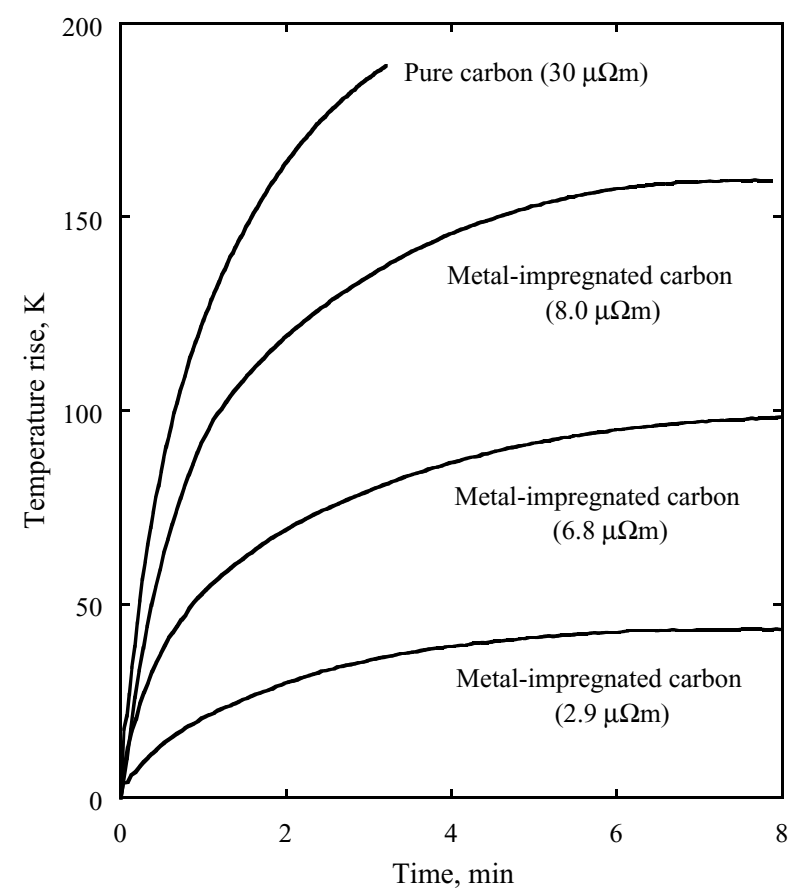

Fig. 1 Temperature rise of contact wire near contact point (Current: $100 \mathrm{~A}$ )

Most recently, one JR company reduced the number of contact strips on a pantograph by half and, therefore, doubled the current density through a contact strip. When the current density at the contact point doubles, serious problems arise. One is that a greater contact-break arc discharge might cause increased wear of the contact strip and heavier damage to the strip surface, where metal migration might occur. Another is that it might be difficult to suppress the temperature rise of the contact wire when at a standstill to keep it within the limit because of the rise of resistivity on the strip surface caused by the metal migration. ${ }^{3)}$

When the material is used under conditions in which contact breaks between contact strip and contact wire often result in arc discharge, the metal content of the carbon-based material is said to migrate from the strip surface to the outside of the material. This metal migration could degrade the electrical conductivity on the surface and wear down the resistance of the strip material.

In order to solve these problems, two carbon contact strip materials with a resistivity lower than about $1 \mu \Omega \mathrm{m}$ were developed. One was made by impregnating copper into porous carbon to increase its copper and graphite content as well as its electrical conductivity. ${ }^{4)}$ The other involved the application of a carbon-fiber reinforced carbon composite material (C/C composite) which was impregnated with copper-titanium. ${ }^{5)}$ These two materials are also used on DC electric vehicles operated by JR companies.

\subsection{Carbon contact strip materials for Shinkansen}

In the case of Shinkansen vehicles, the few carbonbased materials that have been used as pantograph contact strips have been for experimental purposes only.
However, intensive efforts have been made over the last decade to develop and introduce applicable materials. Several offering satisfactory performance from the mechanical strength and wear standpoints were developed and tested on actual Shinkansen vehicles. ${ }^{6)}$

One of these materials is a copper-alloy-impregnated carbon, named SX801, with a base carbon material consisting of carbon powder and chopped carbon fibers that are less than $20 \mu \mathrm{m}$ in diameter and $2 \mathrm{~mm}$ in length. Mixing with chopped carbon fibers results in improved mechanical strength.

After full-sized laboratory testing, which included mechanical impact tests, SX801 has been mounted and tested on the pantographs of several Shinkansen, the principal results of which are shown in Table 2. No chipping or cracks were detected in the material after the tests. According to these test results, the wear performance of SX801 was confirmed as being comparable to that of sintered metal alloy strips.

Table 2 Principal results from Shinkansen carbon contact strip field tests

\begin{tabular}{|l|c|c|c|}
\hline Type of vehicle & $952 \& 953$ & 925 & 200 \\
\hline Test line & Tohoku / Joetsu & Tohoku & Joetsu \\
\hline Distance $(\mathrm{km})$ & 9,300 & 1,100 & $7,700 \sim 19,100$ \\
\hline $\begin{array}{l}\text { Pantograph } \\
\text { configuration }\end{array}$ & $\begin{array}{c}2 \text { pantographs } \\
\text { per } 3 \text { circuits }\end{array}$ & $\begin{array}{c}1 \text { pantograph } \\
\text { per } 1 \text { circuit }\end{array}$ & $\begin{array}{c}2 \text { pantographs } \\
\text { per } 5 \text { circuits }\end{array}$ \\
\hline Maximum speed $(\mathrm{km} / \mathrm{h})$ & 315 & 210 & 210 \\
\hline Wear rate $\left(\mathrm{mm} / 10^{4} \mathrm{~km}\right)$ & $3.8 \sim 4.9$ & 3.1 & $3.0 \sim 4.0$ \\
\hline
\end{tabular}

\section{Development of the installation method for carbon contact strips}

\subsection{Current installation method and its problem areas}

The method for installing carbon contact strips on the pantograph head is a long-standing and important operational problem. Since the carbon material is brittle, unlike sintered metal alloys, it is difficult to cut a female thread in the strip itself with which to screw it on to the pantograph head. Hence the carbon contact strips are generally manufactured with a dovetail base that can be clad with a close-fitting steel sheath. This steel sheath is a fabricated metal holder that grips a full-length carbon strip and has square-headed screw bolts for mounting it on a pantograph head. To install the carbon strip using this method, pantograph heads will normally be modified from those with sintered metal strips. In most cases, although the carbon material itself is of lighter weight than sintered metals, the pantograph head with carbon strips is heavier. Recent high-speed trains have been equipped with aerodynamically smooth pantograph heads in order to reduce aerodynamic noise. The carbon contact strip with a steel sheath cannot be installed easily on these newly developed pantographs.

To solve this problem, the authors have considered, examined and developed the following three methods to install carbon contact strips:

(1) Unifying the installation bolts and steel sheath

(2) Direct bonding of contact strip to pantograph head 
(3) Installation of $\mathrm{C} / \mathrm{C}$ composite contact strips with screws

This chapter describes the development of the three installation methods.

\subsection{Unifiying the installation bolts and steel sheath}

One of the problems of the existing carbon contact strip is its thickness. The carbon contact strip requires a base thick enough to allow cutting a slot to contain the square head of the installation bolt. If this slot and square bolt head can be omitted, the contact strip can become thinner and be installed on downsized, aerodynamic, lownoise pantograph heads.

In order to reduce the number of parts, built-in bolts are widely used in the automobile industry as fasteners to bind parts to steel plates. The headless bolt, which is built into the plate, has teeth-marks to bite the plate at the end and is pressure inserted into the hole in the plate. The authors have applied this built-in bolt as an installation bolt and investigated its mechanical properties in laboratory tests.

3.2.1 Effect of unifying the steel sheath and installation bolt

Figure 2 shows the cross section of a contact strip with the current installation bolt and that with the builtin bolt. In the case of the latter, the total thickness of the contact strip can be $20 \%$ thinner.

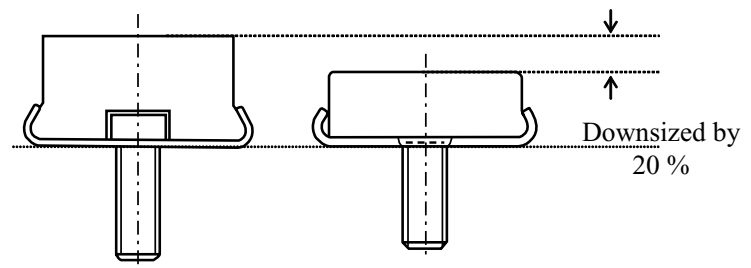

(a) With a square-headed bolt (b) With a built-in bolt

$$
\text { (Current design) (New design) }
$$

Fig. 2 Cross section of the contact strip with an installation bolt

\subsubsection{Mechanical strength of built-in bolts}

The built-in bolts fastened to the steel sheath need to be of sufficient strength not to be broken when tightened. The binding strength of the sheath and a built-in bolt was measured by deformation torque and shear strength and compared with that of the current design.

When a bolt is being tightened with a nut, the torque increases gradually and stops increasing at a value

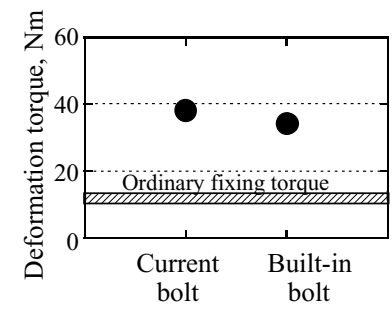

(a) Comparison by deformation torque

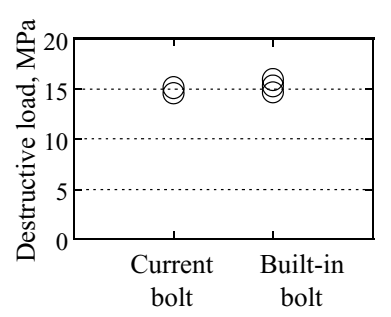

(b) Comparison by destructive shear load
Fig. 3 Comparison of binding strength between current and built-in bolts known as the deformation torque. The deformation torque of the built-in bolt was measured to be $34.3 \mathrm{Nm}$, which is almost comparable (Fig. 3 (a)), as was the load that was added to shear the bolt (Fig. 3 (b)).

\subsubsection{Built-in bolt durability}

Because contact strips are used for between 1.5 and 2 years on conventional narrow-gauge line pantographs, their binding strength decreases due to corrosion. Therefore, the durability of the binding was evaluated by brine dipping tests.

A steel sheath with built-in bolts was dipped in 5\% brine for a given period of time, exposed to the atmosphere and investigated for the effect of rusting. The deformation torque and the electric resistance between sheath and built-in bolt were also measured.

After having been dipped in brine for 175 days and exposed to the atmosphere for 202 days, the sheath with built-in bolts was heavily rusted. After having been dipped in brine for 31 days and exposed to the atmosphere for 161 days, or after exposure to the atmosphere for 1.5 to 2 years, slight rust was found on the screw thread portion of the built-in bolt.

Only the electric resistance of the 175-day dipping, 115-day exposure specimen had increased to $0.65 \mathrm{~m} \Omega$ but the other specimens showed the same resistance as that of new ones. All specimens showed the same deformation torque as that of the new ones.

These results show that the binding between built-in bolt and steel sheath has sufficient durability for operational use. Therefore, it can be concluded that the bolt built in to the steel sheath can be used for contact strip installation purposes.

\subsubsection{Summary}

(1) When a $1.6 \mathrm{~mm}$-thick steel sheath and a built-in bolt are used, the thickness of contact strip necessary to guarantee the same allowance of wear as that of the current type can be reduced by about $20 \%$.

(2) There are neither decreases of mechanical strength nor deterioration in the binding region of the builtin bolt when it is used in the normal environment.

\subsection{Direct bonding of contact strip to pantograph head}

When carbon contact strips containing metal are bonded firmly to the aluminum pantograph head with adhesive, considerable reductions in size and weight can be achieved.

3.3.1 Examples of attaching contact strips with adhesives

In some high-speed railways in Europe, pure carbon contact strips are generally bonded to the aluminum pantograph head. ${ }^{7)}$ Because carbon contact strip materials used in Japan contain a higher metal content and have less void pores to improve their mechanical strength and electric conductivity, it was necessary to find suitable adhesives, electric conductive filler materials and application requirements different to those used in Europe.

The authors have investigated a number of adhesives and fillers, as well as their application requirements and 
have developed a bonding method that brings about greater adhesive strength and lower electric resistance in the adhesive layer than that used in Europe. The results of some experiments that involved contact strips being bonded to an aluminum pantograph head by the newly developed method are described below.

\subsubsection{Adhesive layer temperature dependence}

The effect of temperature on adhesive strength was measured and plotted for a metal-impregnated carbon and aluminum pair bonded using the newly developed method, and for a pure carbon and aluminum pair used in Europe, as shown in Fig. 4. At any temperature, the adhesive strength obtained by the newly developed method is greater than that of European products. Because the adhesive strength declines sharply at above $150{ }^{\circ} \mathrm{C}$ even with the new method, constant monitoring to confirm that the temperature in being maintained under the critical temperature of about $150{ }^{\circ} \mathrm{C}$ is advisable, in order to use the direct bonding method.

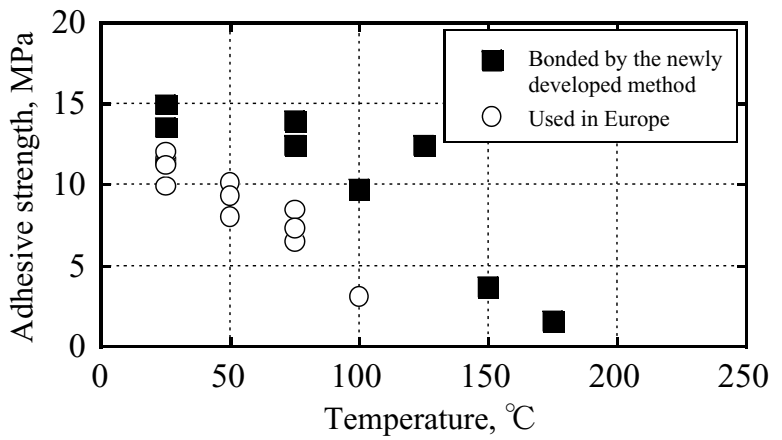

Fig. 4 The effect of temperature on adhesive strength compared with adhesives used in Europe

\subsubsection{Temperature rise at the adhesive layers}

Since an adhesive layer conducts electricity, Joule heat is generated by its resistance. If this heat is high enough to raise the temperature of the layer, adhesive strength will diminish. A test piece was made comprising contact strips bonded between two square aluminum pipes. An electric current was passed from the aluminum pipe on one side to that on the other through two adhesive layers and the contact strip material. The temperature rise caused by the heat generated in the adhesive layers was then measured.

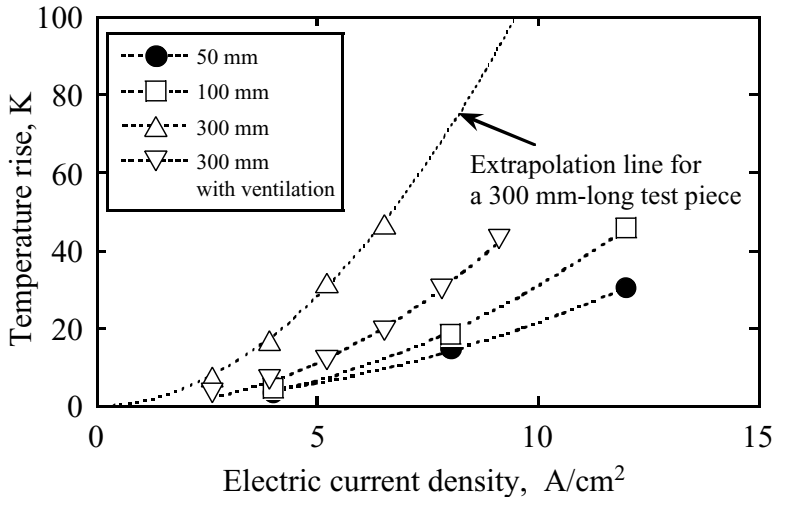

Fig. 5 Temperature rise in the adhesive layers and electric current density
Figure 5 shows the relationship between the current density in the adhesive layers and the temperature rises in test pieces of different sizes. In the case of the 300$\mathrm{mm}$ test piece, which is equivalent to the actual size of a contact strip, the temperature rise was about $47 \mathrm{~K}$ at the current density of about $6.5 \mathrm{~A} / \mathrm{cm}^{2}$, with a large allowance of about $110 \mathrm{~K}$ against the critical temperature.

\subsubsection{Evaluation of electrical and mechanical properties with actual contact strips}

Heat sources that affect the temperature of the adhesive layer consist of the resistance of the contact strip itself, the contact resistance between the contact strip and contact wire, the friction of contact strip with the contact wire and the contact break arc discharge. On the other hand, the air flow passing over actual pantographs when in operation has a cooling effect.

The temperature at the adhesive layer is governed by the balance between the heat generation and dissipation. To simulate the temperature at the adhesive layer of an actual contact strip, a sliding contact experiment was performed under an electric current with the contact strip bonded to a real pantograph head. The temperature at the adhesive layer was measured at electric currents from 200 to $400 \mathrm{~A}$ and sliding speeds of between 20 and $300 \mathrm{~km} / \mathrm{h}$.

When plotted against the contact loss ratio, the temperature rise has a linear relation regardless of the electric current or the thickness of contact strip (Fig. 6). This result shows that the influence of the heat generated by the contact break arc discharge is dominant in the temperature rise in the adhesive layer over that caused by the resistance of contact strip itself and the contact resistance between the contact strip and contact wire. The maximum temperature rise in the experiments was about 50 to $60 \mathrm{~K}$. Hence, there is a safety margin of about 100 $\mathrm{K}$ against the critical temperature.

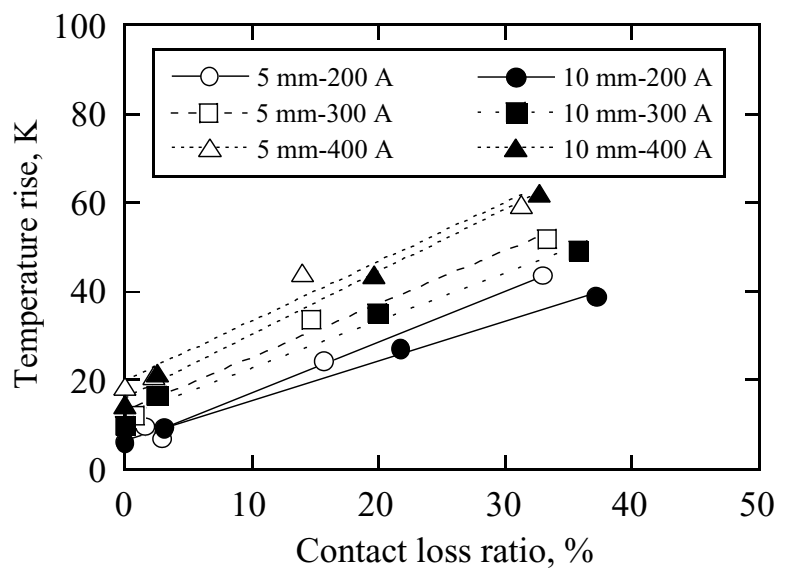

Fig. 6 Temperature rise in the adhesive layer in sliding contact test under electric current and with frequent occurrence of contact break arc discharge

\subsubsection{Several problems associated with bonding}

If carbon contact strips and an aluminum pantograph head, which have differing heat expansion coefficients, are bonded with adhesive at a fixed treatment temperature, the carbon-aluminum bonding will bend at tem- 
peratures other than that at which the adhesive was applied. When it bends to a large extent, the bonding may break. According to a rough calculation using a bimetal model ${ }^{8)}$, the maximum stress produced in the adhesive layer is about $0.3 \mathrm{MPa}$. Figure 7 shows the roughly calculated amount of warp and the stress that occurred when the warp is reformed. Several warp measurement results are also shown. Although the maximum stress that occurred at reformation was about 0.3 $\mathrm{MPa}$, this is less than $3 \%$ of the adhesive strength of carbon-aluminum bonding.

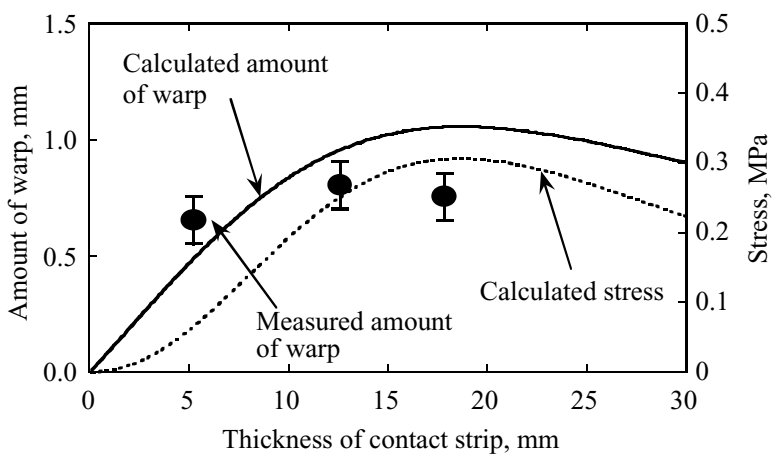

Fig. 7 Amount of warp and stress that occurred when warp is reformed

\subsubsection{Summary}

(1) Under the newly developed method, the temperature rise at the carbon contact strips' adhesive layer when bonded with an aluminum pantograph head is about 50 to $60 \mathrm{~K}$, providing a large safety margin against the critical temperature, when the electric current passes through the layer.

(2) According to a sliding contact test under an electric current, the heat generated by contact break arc discharge significantly contributes to the temperature rise at the adhesive layer. Therefore, if direct bonding of the contact strip is applied to an actual pantograph, it will be necessary to examine the conditions under which contact is lost and the electric current density in the contact strip.

\subsection{Installation of $\mathrm{C} / \mathrm{C}$ composite contact strip with screws}

In the case of a $\mathrm{C} / \mathrm{C}$ composite material, female threads can be cut easily. Because a $\mathrm{C} / \mathrm{C}$ composite has the two-dimensional textile structure of carbon fiber, cracks do not progress easily from a screw thread to the material (Fig. 8). The authors have already developed a
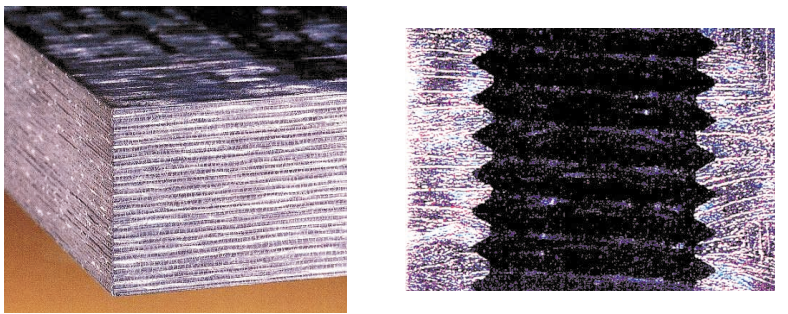

Fig. 8 Textile structure of $\mathrm{C} / \mathrm{C}$ composite (left) and female threads cut in $\mathrm{C} / \mathrm{C}$ composite (right) contact strip made of metal-impregnated C/C composite. The results of laboratory and field tests applied to $\mathrm{C} / \mathrm{C}$ composite contact strips fitted to a pantograph head with screw bolts follow:

\subsubsection{Mechanical strength of a female thread in a $\mathrm{C} / \mathrm{C}$ composite}

The mechanical strength of a female thread cut into a $\mathrm{C} / \mathrm{C}$ composite contact strip was measured and compared with that cut in a sintered metal alloy contact strip. Pieces in which a female thread had been cut were prepared to various thicknesses and load added to the thread with a bolt. The load when the thread was destroyed was measured. Figure 9 shows the results. Although the destructive load on a female screw increases as the effective screw length becomes longer, the rate of increase differs with different materials. The female thread cut in a 9-mm-thick $\mathrm{C} / \mathrm{C}$ composite has a strength equivalent to that cut into a $3-\mathrm{mm}$-thick sintered metal alloy which is at its wear limit.

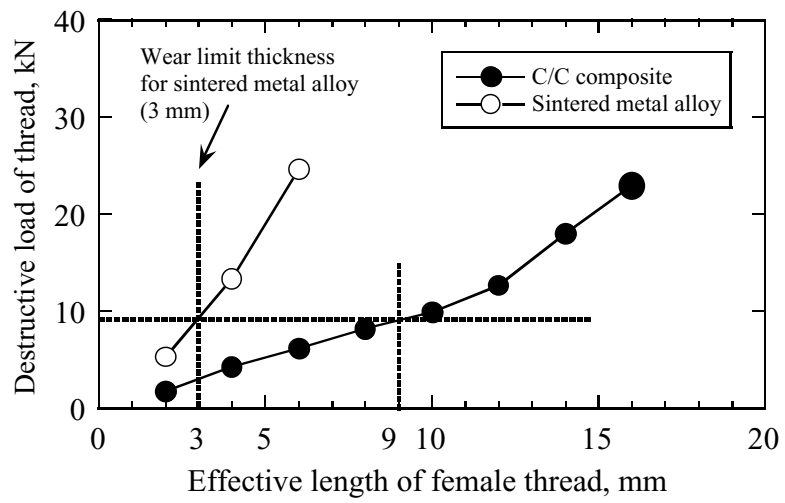

Fig. 9 Effective length of female thread and destructive load of thread

\subsubsection{Electrical properties}

When a C/C composite is attached using screw bolts, the screw thread cut into the composite material may become an electric current path. When an electric current passes only through the contact area between the composite and the bolts, Joule heat will be generated by the resistance at this contact area, where the temperature rise caused by the heat may degrade the contact materials and loosen the bolts.

The temperature rise at the contact area when an electric current of 400 A passes only through the screw thread was measured. The result shows that the maximum temperature rise is about $20 \mathrm{~K}$, which is unlikely to have any effect on the materials. In the same manner as the direct bonding of the contact strip, the heat caused by the contact break arc discharge when sliding under an electric current may affect the materials. Tightening of the screw bolt was investigated after sliding under an electric current and frequent occurrence of arc discharge. The tightening of the bolt was evaluated by measuring the torque needed to unscrew the bolt. The result shows that this was within tolerance.

\subsubsection{Verification of durability by field testing}

$\mathrm{C} / \mathrm{C}$ composite contact strips were attached using 


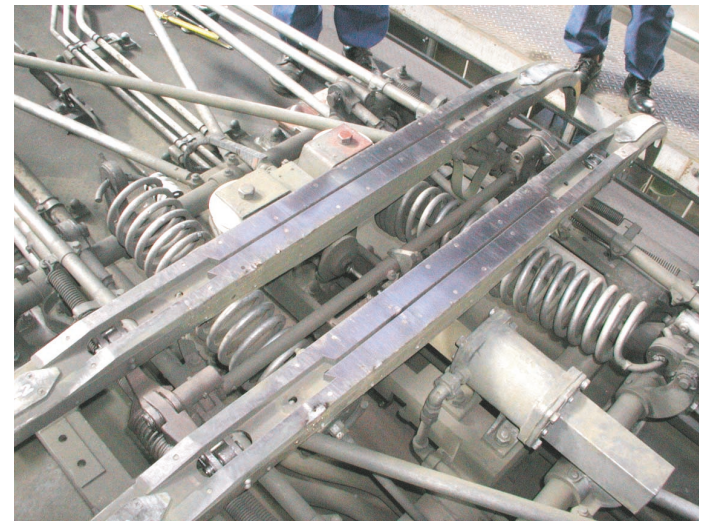

Fig. $10 \mathrm{C} / \mathrm{C}$ composite contact strips attached on actual pantograph using screw bolts

screw bolts on the pantograph head of an actual electric vehicle (Fig. 10), and the durability of the female screw thread cut into the composite investigated. Used for the test was an electric commuter-type vehicle whose maximum electric pantograph current was about 1,190 A. After six months of use, the contact strips were removed from the pantograph head and investigated. The result shows that loosening of bolts was not measured and that neither dents nor deficits were found in the screw thread of contact strip.

\subsubsection{Summary}

(1) A female thread cut into a 9 -mm-thick $\mathrm{C} / \mathrm{C}$ composite has a strength equivalent to that cut into a $3-\mathrm{mm}$ thick sintered metal alloy, which is at its wear limit.

(2) The temperature rise at the contact area when an electric current of 400 A passes only through the screw thread was about $20 \mathrm{~K}$, which is unlikely to have any effect on the materials of pantograph.

(3) $\mathrm{C} / \mathrm{C}$ composite contact strips were installed with screw bolts on the pantograph head of an actual electric vehicle. The durability of the female screw thread cut in the composite was investigated and confirmed on the pantograph head of the actual electric vehicle.

\section{Conclusions}

The results of laboratory or field tests to evaluate or verify the reliability and durability of three newly developed installation methods for metal-impregnated carbon contact strips can be summarized as follows:

(1) The steel sheath with built-in installation bolts can maintain sufficient binding strength and durability with contact strips fitted under normal conditions. Therefore, the contact strips with the developed steel sheath can replace the existing ones.

(2) The contact strips bonded to the pantograph head by the newly developed bonding method can also maintain sufficient strength and durability when sliding under electric current and in frequent occurrence of arc discharge. However, further evaluation in field tests is required before they can be used operationally.

(3) The reliability and durability of $\mathrm{C} / \mathrm{C}$ composite contact strips installed with screw bolts on a pantograph head have been confirmed in field tests.

Unifying the installation bolts and steel sheaths as well as the direct bonding of contact strips to a pantograph head were carried out by a joint $R \& D$ contract between RTRI, Toyo Tanso Co., Mitsubishi Materials Corp. and Toyo Denki Seizo. The installation of $\mathrm{C} / \mathrm{C}$ composite contact strips with screws was developed under a joint R\&D contract between RTRI, Finesinter Co. and Across Co.

\section{Acknowledgement}

The authors greatly appreciate the cooperation of Sagami Railway Co., which supported the field testing of the $\mathrm{C} / \mathrm{C}$ composite contact strips.

\section{References}

1) Kubo, S., Tsuchiya, H. \& Ikeuchi, J.: "Wear Properties of Metal / Carbon Composite Pantograph Sliders for Conventional Electric Vehicles," Quart. Rep. of RTRI, Vol.38, No.1, pp.25-30, 1997.

2) Tsuchiya, H., Kubo, S. \& Nagasawa, H.: "Development of Carbon Contact Strip of Pantograph for High Electrical Current Collection," WCRR2001, Document No.155, Cologne, Germany, 2001.

3) Kubo, S. \& Kato, K.: "Effect of Arc Discharge on the Wear Rate and Wear Mode Transition of a CopperImpregnated Metalized Carbon Contact Strip Sliding against a Copper Disk," Tribology Intl., Vol.32, No.7, pp.367-378, 1999.

4) Kubo, S., Tsuchiya, H. \& Ikeuchi, J.: "Development of Metallized Carbon Contact Strips with Higher Electrical Conductivity and Less Wear," Extended Abstracts, 1st World Conference on Carbon (EUROCARBON 2000), pp.381-382, Berlin, Germany, 2000 .

5) Kubo, S., Tsuchiya, H. et al.: “Application of MetalImpregnated Carbon-Carbon Composite to Contact Strips of Pantograph," Extended Abstracts, 1st World Conference on Carbon (EUROCARBON 2000), pp.767-768, Berlin, Germany, 2000.

6) Kubo, S., Tsuchiya, H. \& Ikeuchi, J.: "Development of Metal/Carbon Composite Pantograph Contact Strips for the Shinkansen Electric Vehicles," Quart. Rep. of RTRI, Vol.38, No.2, pp.76-81, 1997.

7) DIN 43264-3, 1995.

8) Timoshenko, S.P.: "Analysis of Bi-Metal Thermostats,” J. Opt. Soc. Am., Vol.11, pp.233-255, 1925. 